\title{
Building Sport For Development Practitioners capacity for undertaking evaluation - Reflections on a training programme building capacity in Realist Evaluation.
}

\begin{abstract}
At present, the quality and practice of Monitoring and Evaluation (M\&E) in Sport for Development (SfD) projects is under close scrutiny, mainly concerning the capacity that sport has to create social change. Critics have argued that a deeper understanding of 'what works for whom and why' is required when evaluating SfD projects. This paper explores practitioner involvement in $\mathrm{M} \& \mathrm{E}$, drawing upon a 'realist participatory $M \& E$ training framework' developed to train student sport development practitioners to make sense of how and why their SfD projects worked. The training framework was evaluated utilizing a realist approach to understand what approaches to evaluation worked for those involved in the training framework. Specifically, 15 practitioners participated in the training framework encompassing 5 community focused SfD innovation projects delivered within the Coaching Innovation Programme at a south coast university in the United Kingdom. The realist evaluation incorporated Q-method factor analysis with realist interviews and reflective blogs. Findings on the value of realist evaluation for practitioners emerged. Practical and transformational evaluation characteristics unfolded and four groups of practitioners emerged depicting how the training framework worked. These groups were 'new and emerging evaluators', 'polished problem solvers', 'passive passengers', and 'proficient yet sceptical practitioners'. These were underpinned by holistic narratives in line with Q-method demonstrating shared viewpoints about the training framework. In conclusion, participatory approaches of M\&E can work with practitioners and should be embedded to enable application of realist evaluation.
\end{abstract}

\section{Introduction}

Sport for Development (SfD) projects (also referred to as interventions, programmes and initiatives) have proliferated across the globe in the last twenty years._Operating in different contexts, SfD projects have used sport as a tool to address a wide range of different personal and social outcomes, such as sport / physical activity to empower the marginalized (Mwaanga 2011), promote self esteem, tackle health and inactivity (Weed 2016), build community cohesion (Adams 2008) and tackle anti-social behaviour (Crabbe 2007). Moreover, SfD has taken on a considerable role in the social issues agenda, and particularly at present within the UK, there has been a shift for sport and public health to combine (Cabinet Office 2015) to address physical inactivity and obesity (Weed 2016). Thus, in addition to the challenges faced around psycho-social outcomes of sport, such a shift towards the symbiotic relationship between sport, health and physical activity has created crucial implications for how SfD should be evaluated. These implications mainly surround what is deemed as credible in the way of evidence. Within health policy for example the medical paradigm of the experimental Randomised Controlled Trial (RCT) dominates with its capacity to capture what works (Pawson and Tilley 1997). How such approaches can be synthesised with other mixed methods approaches to evaluation involving qualitative, and participatory methods to capture how and why things work (Westhorp 2014), requires careful consideration and attention for SfD projects.

Stemming substantially from debates around M\&E, (Coalter 2013a, Kay 2012), (in international development contexts) a 'lack of evidence discourse' currently exists in respect of the capacity of sport to address wider social goals (Nichols et al. 2011). Coalter (2007, 2010) has emphasised the limited evidence base of SfD, highlighting the prevalence of 'illdefined programmes with hard to follow outcomes' as well as poor M\&E practice. Thus, a field defined by its claims opposed to its results has emerged and sceptics have questioned the 'given' assumption that sport can solve a multitude of problems (Coalter 2007, 2010, Kay 2009, Levermore 2011). As a response to the lack of evidence, a significant increase in the use of M\&E approaches has taken place. Within the UK much of this M\&E work has seen advancements in online packages for SfD projects to capture outputs, outcomes and key 
testimonies for evidencing impact to funders. For example, online M\&E packages such as 'Views' (formulated by Tim Crabbe) have been adopted by key organisations such as the Premier League and Football Foundation where the use of this software by SfD beneficieries is a condition of funding. In addition, mainly within an international context (Levermore 2011), the log frame (using logic models and top down matrices to quantify findings through inputs to outputs and outcomes) have been prominent approaches. However, Levermore and others (Lindsey and Gratton 2012) have been critical of log frame approaches as they can be perceived as too rigid and not conducive for community development settings. The question of 'does sport work' is firmly rooted in SfD's approach to evidence. Funders and politicians who invest money and resource into SfD want to see results and impact. Thus, it is of little surprise that the point of departure for any approach to $M \& E$ may be to find evidence to support positive outcomes, or show proof (Harris and Adams 2016) that programmes work (Smith and Leach 2010).

Key issues remain in understanding how and why, and for whom projects create outcomes (Pawson and Tilley 1997). Harris and Adams (2016) have called for theory-driven approaches that focus on Pawson and Tilley's (1997) 'realist evaluation' to understand how and why projects work, for whom and in what circumstances. Realist evaluation has developed specific momentum across a wide variety of sectors in the last 10 years; specifically within the healthcare and nursing sector (Abhyanker et al. 2013, McConnell et al., 2016) and also in participatory settings (Jagosh et al. 2012). However, its mobilisation within SfD has been limited at best. Aside from Nichols (2007), Richards et al. (2012) and Duffy et al. (2013), few have attempted to apply it and whilst there exist participatory approaches to evaluation that may mobilise theory of change (Levermore 2011), there are few attempts to mobilise practitioners to carry out realist or theory driven approaches within SfD. Reasons for this may be connected with the traditional approaches of M\&E in SfD to capture outcomes as opposed to the processes that lead to them (Coalter 2007) and the evangelical nature of SfD which navigates towards proving success and effectiveness (Smith and Leach, 2010). Given realist evaluation's capacity to make sense of complexity, and how and why projects work, one could question why the SfD field has not mobilised it with consultants, academics and indeed practitioners, who operate at the coalface of project delivery. This is the case despite various authors calling for aspects of its use (Sugden 2010, Coalter 2007, Harris and Adams 2016).

Of the multiple approaches to $\mathrm{M} \& \mathrm{E}$ available to the industry, few are implemented by practitioners (Harris and Adams 2016) and there is limited use of approaches that occupy a realist orientation. In fact, many of these approaches are carried out either by academics independently (Kay 2012) or within participatory frameworks that may involve practitioners to different extents (Levermore 2011). As Adams and Harris (2014) assert, much of the work that practitioners undertake is monitoring opposed to evaluation. Tracking participation levels in accordance with performance indicators (Smith and Leach 2010) is now common in SfD practice. Involving practitioners more closely in M\&E work holds significant scope to develop the evidence base of SfD because practitioners are entirely contextualised within their projects and are well placed to make sense and reflect upon to the extent to which any change is manifesting itself. Deeper practitioner engagement with evidence based practice may help to address many of the subjugating (Nichols et al. 2011) power imbalances omnipresent in a lot of M\&E practice (Harris and Adams 2016) because it places value upon 
their role and the insight that they have. Whilst the enactment of M\&E requires a certain competency which practitioners may not possess due to limited training (Hylton and Hartley 2011, Coalter 2013a), this can be mitigated providing that appropriate capacity building and training is put into place (Fetterman 2001). The contribution practitioners make towards $M \& E$ and the learning they receive from such practice could form a key area of focus for any evaluation work (Nichols et al. 2011, Kay 2012). Furthermore, given the scope of the realist approach introduced previously, Harris and Adams (2016) argue for such approaches to be embedded and built into practitioner work that may help to bring the practitioner voice more clearly to life.

This paper discusses findings from the evaluation of a collaborative M\&E training framework developed for practitioners delivering SfD projects at a university in the south of the UK. The purpose of the training framework was two/fold. First, it sought to build the capacity of practitioners to develop a realist programme theory (Pawson and Tilley 1997) to hypothesise (prior to delivery) how, why and for whom their projects may work. Second, whilst delivering their projects, the training framework built their capacity to then evaluate and test their programme theories through realist evaluation. This consisted of a range workshops focusing on building capacity (Schula et al. 2016) in developing programme theory, testing programme theory and analysing data to draw findings.

The training framework was then evaluated utilising realist-orientated mixed methods of Qsort (Watts and Stenner 2012), blogs and interviews to make sense of how and why and for what kinds of practitioners the training framework produced certain outcomes. Key conclusions are made around what approaches to $M \& E$ work best for practitioners in the field of SfD and the lessons that can be learned for developing M\&E practice.

\section{Positioning Realist Evaluation as an appropriate M\&E approach in SfD}

Pawson and Tilley's (1997) realist evaluation offers significant potential for the SfD field. They point out that a key focus for understanding social change is to not justify 'what works' but to explicate what it is about a project that makes it work or not. Pawson and Tilley emphasise the role of context in social change projects because the conditions, environments, socio-economic backgrounds and characteristics of the participants involved in a given project will influence project outcomes (Westhorp 2014, Dalkin et al. 2015). It is not possible to generalise the success of a project to another location because social projects are context dependent and they are complex. Pawson and Tilley also afford significant attention to causality, which for them is conceptualized as the 'generative' behavioural triggers and mechanisms that a project may bring about (Pawson and Tilley 1997), placing emphasis on how reasoning, attitudes and behaviours of participants intersect with the resources of a project. The realist evaluator understands causality in terms of underlying causal mechanisms generating regularities which may often be hidden (Pawson and Tilley 1997, Tilley 2000) and moves beyond attributing project success or failure to one sole cause. In essence, realist evaluation epitomises equifinality in that there are many causes to an outcome. It is not possible therefore to simply observe and make observations around what works and attribute causality to one thing, as this is reductionist (Byrne and O'Callaghan 2013).

A realist approach to evidence involves understanding what works for whom in what circumstances and why (Pawson and Tilley 1997). Their contribution is clear in that it is not social projects per se that make people change, but the very people themselves based on their 
reasoning and interactions within the context of the project (Dalkin et al. 2015). On a pragmatic level, Pawson and Tilley and the many who have followed in their footsteps (eg Westhorp 2014, Dalkin et al. 2015) suggest that social programmes (or projects as referred to in this paper) are 'programme theories incarnate' constituting assumptions and beliefs of how and why a programme should work (Funnell and Rogers 2011). Thus, the first step in any evaluation is to establish a programme theory (PT) for testing, made up of 'candidate' (CMO) Context - Mechanism - Outcome configurations (Pawson and Tilley 1997) where:

$-\mathrm{C}=$ what conditions are in place for a project to trigger mechanisms to produce outcome patterns?

$-\mathrm{M}=$ what is it about a project that may lead it to have a particular outcome pattern in a given context (for example, how do resources intersect with participants beliefs, reasoning, attitudes, ideas and opportunities?)

$-\mathrm{O}=$ what are the practical effects produced by causal mechanisms being triggered in a given context?

Having established a programme theory, realist evaluation then involves mobilising mixed methods (qualitative and quantitative) to test it, establishing what worked for whom in what circumstances and why leading to a refinement of a new programme theory. The scope and potential for realist evaluation's use in social change is significant given that inputs and resources contribute to project outcomes and outputs. However, how these outcomes emerge is often unclear and referred to as the 'black box' (Astbury and Leeuw 2010). Realist evaluation attempts to demystify the darkness by identifying the mechanisms activating (Dalkin et al. 2015) inside projects. Very recently Dalkin et al. (2015) have gone even further to help 'disaggregate' (pg. 1) the programme mechanism into resource and reasoning. Quite simply, they state that within any social change project, resources are released into contexts, and these are reacted to and reasoned against by programme stakeholders to create outcomes.

The argument for realist programme development and evaluation for SfD is compelling because SfD projects are socially context dependent involving human volition and change mechanisms. Sport may work for some people in certain circumstances in which they are often combined with other interventions and resources. Indeed, whilst sport might provide the context for positive development, understanding how and why social processes combine to explain SfD's contribution (Coalter 2013b) could be a key focus.

As highlighted previously limited evidence exists of approaches that involve practitioners in developing and carrying out realist evaluation. With the exception of some (Bloyce and Smith 2011, Hylton and Hartley 2011, Piggin et al. 2009) the world of the practitioner and how they engage with evidence is an unknown terrain. In accordance with Harris and Adams (2016), Kay (2009), and Welty Peachy et al. (2015), closer collaboration is needed with practitioners to involve them with $\mathrm{M} \& \mathrm{E}$. This may involve collaborative approaches to engagement (with academics and funders) where practitioner knowledge informs approaches to M\&E (Schula et al. 2016). A more reflexive learning culture (Edwards 2015) could be embedded in inclusive training programmes for practitioners where $M \& E$ capacity can be increased. Given the proliferation of courses in Higher Education whereby students gain experience in SfD in connection with their studies (Bruening et al. 2015, Hayton 2017), it would seem sensible for students to develop this reflexivity through closer engagement with research and field work (Welty Peachy et al. 2015), developing key skills for industry. 


\section{Presenting a realist collaborative M\&E training framework}

The M\&E training framework was constructed with the intention to enable practitioners delivering small scale SfD projects to carry out realist M\&E of these projects.

The training framework was piloted within the Coaching Innovation Programme (CIP) at a university in the south of the UK. The CIP is student-led, and curriculum-based enabling small groups of students to research the needs of a community and develop their own SfD project with local stakeholders. The projects are developed over one entire academic year (eight months). Initially, students work to build a realist programme theory through engaging with partners, communities and establishing need. This is then followed by delivery of their project and its evaluation the following academic year. The CIP itself currently reflects a significant volume of SfD activity in the area, reaching one thousand beneficiaries every year and spanning sport and public health agendas.

\section{The training framework}

The focus was to build the capacity of practitioners to mobilise realist evaluation in their projects to make sense of how and why they worked. For clarity five diverse projects voluntarily opted into the training framework:

- Edumaths: A physical activity project delivered in a local primary school to address physical literacy and bring movement based education into the maths curriculum.

- Heart of the community: A chair based physical activity project designed to tackle isolation and loneliness for over 60's.

- Gateway: A college based project working with less academic young people using sport to develop employability skills.

- Mums on the move: A physical activity project using Zumba to encourage sedentary mums living in a deprived area to get active.

- Mentor me: A project in a local secondary school designed to train pupils aged 15-16 years to coach and mentor younger peers disengaged from PE.

The training framework was implemented in accordance with participatory evaluation whereby the practitioners were mobilised and trained to develop and test programme theories through realist evaluation. Participatory evaluation involves trainers working with stakeholders to determine what is to be evaluated and how it will be evaluated (Cousins and Whitmore 1998). The participatory focus here attempted to take into consideration context, and what was needed for the practitioners in their own project evaluation, whether practical (outcomes and learning that come about to improve the project) or transformational (changing an individual's disposition towards evaluation practice and learning) (Cousins et al. 2013).

\section{Training framework delivery}

Involvement in the training was entirely optional and delivered as an extension to the curriculum that the practitioners were involved in. It comprised two distinct phases and a series of workshops. Phase 1 'Programme theory conceptualisation' provides guidance for 
practitioners to address the first stage of realist thinking by developing a programme theory of how and why they see their project working.

Phase 1 begins with the practitioners broader statement of intention which is based on initial assumption and belief of what is needed. The first task is to establish and research the field through situational analysis (Funnel and Rogers 2011) establishing needs and mapping the area in which the project will take place. Having completed this task, practitioners are able to then make explicit the key outcomes and illustrate the anatomy of their project which should reflect the contextual factors underpinning their project.

The last task of phase 1 is made up of conjecturing how and why their project will work for certain people in certain circumstances making use of Pawson and Tilley's (1997) CMO configuration. This, specifically draws upon Dalkin et al's. (2015) innovative critique of the CMO configuration (see figure 1) which addresses a key issue in breaking down and making sense of what a mechanism is into resource and reasoning. This way of theorising the CMO into CMMO enables practitioners to hypothesise how they see their participants reasoning.

Figure 1: Conceptualising programme theory Dalkin model

Here

Phase 2 outlines the key 'realist' M\&E stages that the practitioners followed throughout their project to test their programme theory. Each of these stages were accompanied by workshops with an evaluation facilitator to build understanding and capacity at each stage of their evaluation of their project.

Figure 2: Mobilizing M\&E

Here

In order to encourage fluidity and avoid linearity the training framework recognised the differing stages that each project was at concerning their M\&E. Thus, each workshop was delivered and repeated in accordance with those stages.

\section{Methodology}

A realist evaluation methodology was designed to understand what it was about the $\mathrm{M} \& \mathrm{E}$ training framework (Pawson and Tilley 1997) that would lead to specific outcomes for the practitioners involved. The evaluation focused on specifying the generative mechanisms of change (Pawson and Tilley 1997) within the M\&E training framework. It was essential therefore to investigate how and why the practitioners reasoned towards the resources provided (mechanisms) to foster M\&E practice.

The methods selected for this study were made up of Q-method (Watts and Stenner 2012), interviews and blogs. Q-method focuses on subjective viewpoints of its participants (Watts and Stenner 2012, Brown 1980), asking them to decide what is 'meaningful' and what does (and what does not) have value and significance from their perspective (Watts and Stenner 2005). Q-method involves developing a set of statements representing the viewpoints of certain individuals about an issue, programme or phenomena. These statements (known as the 
Q-set) are then ranked by participants (known as the P-set) relative to one another into piles of agreement (e.g. +4, +3), disagreement (eg.-4, -3) and neutral (e.g. 0) feeling by use of a ' $Q$ grid' depicted below in figure 3 (Watts and Stenner, 2012). This culminates in the production of a Q-sort for each participant. Factor analysis is then statistically implemented to identify shared correlations of viewpoints amongst those individuals creating sub/groups of the participants with their own overall Q-sort. The statistical data within each sub/group is then qualitatively interpreted by the researcher to produce a story or holistic narrative about those shared view points (Watts and Stenner 2012).

Figure 3: Example Q-sort grid

Here

The Q-set in this instance was made up of a total of 30 statements that were ranked accordingly by 15 practitioners ( 6 female and 9 male) into a Q-sort grid (see figure 3 ). This created their own individual Q-sort. The statements (listed in table 1 below) were constructed in accordance with the training framework under evaluation and to test the underlying theory of what it was trying to achieve. They were structured across three key areas; 1 : competency in M\&E, 2: competency in and attitudes towards realist evaluation and 3: feelings about the participatory dimension of the training framework.

Table 1: Q-set statements

Here

The factor analysis identified 8 possible factors (groups) for qualitative interpretation across the 15 completed Q-sorts. Initial analysis of the variance and numbers of practitioners within each group led to four groups being selected for full qualitative interpretation. This was made up of six participants in group 1, four within group 2, three within group 3, and two within group 4. The qualitative interpretation involved examining each resultant Q-sort scores in depth for each group. Thus, in this case four resultant Q-sorts were examined making use of Watts and Stenner's (2012) crib sheet (see below). The crib sheet allowed the researcher to focus upon where certain statements were ranked to allow for the building of a narrative for each group.

Statements ranked at $+4 /+3$

Statements ranked higher in the factor group than any other group

Statements ranked lower in the factor group than any other group

Statements ranked at $-4 /-3$

Distinguishing statements

Using demographical information about participants and micro or macro circumstances

First take - applying logic of abduction (building a story or theory)

Any other additional information 
The crib sheet facilitated an emerging story about each factor capturing shared viewpoints about the training framework. This then led to the production of a provisional 'holistic narrative' (Watts and Stenner 2012) for each group depicting how and why the practitioners reasoned towards the resources provided within the training framework.

\section{Using blogs and interviews to clarify narratives}

Following the Q-method, interviews and blogs were then employed to expand and further explore the narratives. Realist interview schedules were created for each group and a sample of participants from each of the groups were selected (three from group 1, two from group 2, one from group 3, and two from group 4). The interview schedules were designed around the provisional holistic narratives to create a realist interview. This adopted Manzano-Santaella's (2016) 'teacher / learner cycle' which involves an interviewer presenting a programme theory (or testing propositions) to the interviewee who then 'teaches' the interviewer specific components of the programme theory (Manazano-Santaella 2016). This is different to traditional constructivist semi structured interviewing techniques which explore views and opinions about a specific phenomenon, and where the interviewer may control the interviewee (Manzano-Santaella 2016). Instead, a realist interview is carefully aligned to a programme theory under testing because the interviewer asks questions about the theories that the programme assumes (Manzano-Santaella 2016), and these are the subject matter of the interview. The interviewee is then actively involved in responding to what is being asked to reaffirm and / or refine the programme theories. In this study, the Q-method holistic narratives originating from the initial testing of the training framework, acted as the programme theory. These were presented to the practitioners and orientated around specific realist style questioning of 'how', 'why' and for 'whom' seeking increased depth into their reasoning. Practitioners responses offered clarification towards the programme theory and any refinements completing the teacher / learner cycle.

In similar respect to the interviews, a sample of reflective blogs in which participants discussed their feelings towards the training framework were selected and analysed (four from group 1, three from group 2, two from group 3 and one from group 4). These (like the interviews) were all analysed through the use of NVIVO software identifying codes and key themes in accordance with the narratives. This identified the key CMMOs at play in the training framework and informed the final refinements to the narratives.

\section{Results and Discussion}

Each holistic narrative is displayed below, in present tense with the support of statement rankings (Watts and Stenner 2012). For example, in group one ' $1+3$ ' would indicate that practitioners within this group ranked statement 1 at +3 on their Q-sort whereas they ranked statement 29 at -2 . Each narrative is followed by a short discussion of the group with empirical data from the blogs and interviews to support. 
Group one: New and emerging evaluators:

\section{Holistic narrative:}

Viewpoints indicate that the $M \& E$ competency of the practitioners has increased significantly from being involved in the training framework $(1+3)$. It supports the importance of capacity building through the workshops and support to fulfil $M \& E$ tasks. This indicates value placed around practitioners having more responsibility in $M \& E$. However, relative to others they scored lower $(30+1)$ compared to those in groups 2 and 3. This supports their involvement in $M \& E$ yet the near neutral response to $M \& E$ being a key part of a practitioners role is suggested as necessary but not highly essential $(15+1)$. Despite the increased competency and confidence in $M \& E$ in the future $(2+4)$, these practitioners are cautious about how much $M \& E$ should be embedded perhaps due to the time constraints and additional workloads (29-2).

Realist evaluation competency has improved $(3+3)$ which is justified by practitioners indicating their improved understanding of mechanisms within their project (5+4). This is not only a key tenet of realist evaluation but also one of the most problematic where many find it hard to uncover mechanisms. Practitioners have shown clear engagement, and resonance with this $(13+2)$. This is supported with other conceptual elements supporting the realist evaluation process such as the importance of developing programme theories of change (6+2), seeing the value in developing CMMO configurations (4+2) and simply understanding more about how and why their project worked $(12+2)$.

They do not appear to demonstrate any critical issues about realist evaluation which is reflected in their neutral view of it (11-0). This may suggest that although heavily involved, they have relied on others to overcome issues and specific barriers imposed by the evaluation because they may lack that deeper engagement. Furthermore, there is a lack of confidence in the findings of their evaluation having any real impact on the external landscape (24-4) such as partners, partly because they are not critical of that landscape. They are less likely to enhance the use of the evaluation on any transformational level concerning change.

Practitioners demonstrate viewpoints (18-2) that the structure of the training framework did not necessarily enable clear grasping of $M \& E$ (which contradicts $1+3$ ). Yet they rank higher (relative to other groups) the statements associated with the two phases $(7+1 ; 8$ $0)$. This would indicate positive engagement with the structure and guidance based on the contextual needs. Statements 6+2 (developing programme theories of change), 5+4 (improved understanding of mechanisms) and 4+2 (valuing CMO configurations) would support this.

This group were the largest of all and had arguably travelled the furthest in $\mathrm{M} \& \mathrm{E}$ competency. It is therefore apparent that mobilising realist evaluation with this group was positive based on their increased competency and ability to understand why their project was working, and the generative aspects at play. In accordance with the promotion of evaluative thinking (Schula et al. 2016), the following quote demonstrates the strength of the training 
framework for engaging the practitioners beyond simply focusing on the technocratic aspects of evaluation (Chouinard 2013) and attention to outcomes (Adams and Harris 2014):

The workshop sessions really helped us to think more about what was going on in our project. I mean in terms of looking at our resources and investigating how the participants engaged with them.. like our session plans and delivery (Lilly, Interview)

On a pragmatic level, practitioners were able to take the knowledge and understand more about their project, developing the skills needed to uncover mechanisms as the project went along. Running their project alongside the support of the workshops and phases created a sense of responsibility and independence for producing evidence and also realisation that the independent process helped to understand more about how and why their projects worked:

\section{I started to understand it more and the relevance and then I could start applying it. Before, I was sort of not applying it to my project whereas as time went on, I could see more and more how relevant it was to my project. (Mia, Interview).}

This demonstrates the utility of the training framework for mobilising M\&E in a context of limited competency. The depth of participation and decision making enabled the M\&E to be mobilised accordingly within the active mobilisation of the project. Findings such as these advocate clear scope for realist evaluation. First, given the issues surrounding the over reliance on monitoring over evaluation (Harris and Adams, 2016), practitioners may be able to mobilise realist approaches providing there is support and guidance to do so. Second, there is clear potential for practitioners to realise the benefit for mobilising realist evaluation in its capacity to demistify 'how' and 'why' a programme works. Opposed to embracing it on a surface level, this highlights key points surrounding praxis and the way that such an approach may encourage practitioners to reflect on the depth of their projects.

Practitioners valued and recognised the importance of evidence within SfD and became more motivated to understand the evidence in their project. The example below provides evidence of depth of involvement, engagement and reflexivity within the M\&E process:

To begin with it was difficult to understand why the project was not working. This therefore gave us the drive to want to try and understand why. Even if we were unable to reach out to mums in the community, it was important to understand why this is, so that we can develop a new programme theory (Lilly, Blog).

This finding highlights the value in involving practitioners in the creation of realist approaches to evidence in the way that it is able to ignite consciousness about project learning and development. Moreover, in line with (Cousins and Whitmore's, 1998) transformational characteristics of participatory M\&E practice, there are empowering signs (Fetterman 2001) regarding how they are connecting with their evidence and the realisation it brings. Bringing to the surface key questions of 'how and why' may actively promote a critical consciousness about project dynamics that only practitioners themselves see.

Practitioners, however, showed limited stimulation about the critical depth of M\&E and how their findings may influence change.

I don't know. I suppose I don't really think about that. I kind of thought, 
well, why would they be interested. You know, why would they need to know? (Mia, Interview).

Although this group were aware of the importance of evidence, their connection with it was passive and subdued. Despite the evidence of practical outcomes and realisation of new skills on this level, Schula et al's. (2016) assertion that transformative outcomes are embodied by changes in power and control are certainly not as apparent for the practitioners. There would appear limited desire or control over what their findings would change or influence. Practitioners were only able to go so far in influencing their evaluation findings on the practical (Schula et al. 2016) opposed to transformative level (Cousins and Whitmore 1998). This is interesting in that, whilst realist evaluation facilitated the positives findings discussed above, there are still challenges in the confidence that practitioners may have for promoting and communicating its use to wider stakeholders. While it is beyond the scope of the findings of this paper to generalise, perhaps the demands of funders and technocratic discourses (Chouinard 2014) may be culpable for this.

Practitioners made regular reference to the support provided within the training framework as a contributor to their own M\&E work. In order to mobilise M\&E the practitioners responded well to the broken down structure of the workshops where they felt they could steadily clarify understanding and progression with the trainer before moving to the next stage:

Throughout the workshops, you have certain tutorials and sit down meetings, where you can put your questions forward and then you get new problems, issues or questions. So, it was so much like on a fortnightly basis, that we were having the contact and answering our questions. So, anything that we were unsure, we're learning it and taking it forward (Josh, Interview).

Rather than scheduling the workshops at specific and exclusive times, the training framework was designed in a flexible way where the practitioners could make contact in relation to whatever stage they felt they were at. This highlights the importance of fostering meaningful inter-professional relationships which Schula et al. (2016) align to respect, trust, sustained and structured interactivity and cultural competency. Given that in this context, the practitioners grasped realist evaluation, this would suggest that in other contexts of SfD projects should place importance on a structured, interactive and supportive process to foster use and understanding.

This finding would suggest that practitioners carrying out M\&E should collaboratively guide the process to facilitate structured and sustained interactivity (Schula et al. 2016). Whilst this context of Higher Education may be slightly different to conventional SfD landscapes there are similarities and lessons that the external field can take from this training framework if practitioners are the key deliverers of the M\&E. Nevertheless (as supported by this group), realist evaluation and how it is mobilised has significant scope for creating a higher state of consciousness at a practitioner level for addressing many of the issues of evidence in SfD. In particular, such a scope surrounds the way in which practitioners are able to appreciate how and why certain outcomes are unfolding through the mechanism construction and how it informs project development. 


\section{Holistic narrative:}

For practitioners in this group 'use' in $M \& E$ is a prevailing characteristic. Practitioners make use of realist evaluation $(11+3)$ as a suitable evaluation approach for their CIP. Practical outcomes emerge where they are able to understand how and why their project worked $(12+4)$ to meet the goals of their $M \& E$. Actively applying the $M \& E$ through their own project was a key mechanism to this in addition to the support provided $(28+2),(18+1)$. On a transformational level practitioners show willingness to make use of realist evaluation in the future $(14+3)$ and feel that $M \& E$ should be part of a practitioner's role $(30+4)$. This relates to the realisation of understanding how and why their project has worked (12+4). Practitioners within this factor are evaluative thinkers focused on the willingness to learn and gain more skills. Their competency in conducting $M \& E$ has increased $(1+2)$ which is consistent with groups 1 and 4.

The practitioners within this group are more conceptually engaged in sport development and realist evaluation which may explain their desire to use it in the future $(14+3)$ and valuing it as an approach (11+3). Supporting the grasping of realist evaluation, practitioners highly rated the statement of understanding how and why their project worked $(12+4)$. They are engaged in the process and support their understanding of it with additional reading and resources (16+2). This is supported by their ability to identify and solve problems, aligned to their interest in sport development and career aspirations. This conceptual engagement is confirmed given their increased reflexivity and recognition of the limitations imposed by the methodology. They do not place significant approval towards the CMMO configuration (2-0), yet, they make attempts to mitigate these issues through improvisation, support, guidance $(28+2)$ and independence. These transformational aspects are slightly quashed given their limited confidence as to where their findings will make an impact (24-3) which may explain apprehension similar to group 1. Despite this evaluative thinking, they are still apprehensive about carrying out $M \& E$ in the future (2-1) due to the limited perception of how regarded their findings will be.

The practitioners are keen for guidance and support $(18+1)$ and use that support to enable effective M\&E mobilisation. Structure and guidance is needed (28+2) because of their limited experience in $M \& E$. Having a pre-defined training framework enabled practitioners to mobilise $M \& E$ from the outset instead of building it entirely themselves and choosing from other approaches. The viewpoint of lacking control of the evaluation (27-4) does not relate to the design of or participation in the training framework. Interviews and blogs clarified this to relate to the mobilisation of the training framework within the project itself which was open to barriers that made it problematic to mobilise what was intended. Limited time to carry out the $M \& E$ (29-2) and the volatile nature of securing certain stakeholders are examples of such barriers. Practitioners share a positive relationship with the trainer which enabled deeper grasping of concepts $(17+1)$.

There were key characteristics distinguishing practitioners within this group from those in other groups. The first point concerns the level of engagement and awareness of the SfD and 
M\&E landscape surrounding their project. This was a key contextual factor that activated transformational mechanisms associated with following through to realise use and promoting evaluative thinking (Schula et al. 2016) about their evidence.

Many transformational outcomes manifested themselves such as greater value afforded to $\mathrm{M} \& \mathrm{E}$ and willingness to carry out realist evaluation in future practice. A key context leading to these outcomes was the preconceived apprehension afforded to M\&E work:

Prior to the project, I had viewed evaluation as waste of time where professionals collect numerical data and manipulate it to justify their jobs. However, this process of applying realist evaluation has taught me that $M \& E$ is important to identify how changes have occurred so that you can utilise what works to develop a programme or to guide others in building their programmes. (Elvin, Blog).

This emphasises a clear benefit of realist evaluation in its capacity to demystify the black box and provide explanation of what it is about a project that leads to certain outcomes. Moreover, the quote above goes further to demonstrate how practitioners were able to develop a realisation that understanding how and why projects work can actually aid future learning and project development. This mechanism helps to explain positive value afforded to realist evaluation and how it may aid M\&E practice on the practitioner level. This is a major example that links to following through to realise use and promoting evaluative thinking (Schula et al. 2016) whereby a realist approach offers a pragmatic way to make sense of what is taking place within SfD projects. Within this group, realist evaluation has clearly informed the influence of the evaluation as practitioners showed characteristics in line with the practical outcomes of developing new skills and aiding use (Schula et al. 2016):

If you just do a plain monitoring and evaluation and you don't ask those what works for whom and what circumstances and why, you're not going to be given that information and you could go back and you say, Oh, this project overall, it was a success, and you'd go back and you'd redeliver it and it would be a failure and it'd fall through and you'd have no idea why (Teresa, Interview).

So, trying to get it across to kind of big places like Sport England might be quite difficult but for me personally, I'd definitely use it and kind of show people. It definitely had more of an outcome, than kind of you just saying, Oh. this is how many mums we've got and this is what they learned from it. Yeah, I definitely feel confident. (Louise, Interview).

Evidence from this group (like group 1) would suggest that there is value for applying realist evaluation in the field in the future to mitigate M\&E approaches that focus solely on outcomes and technocratic procedures (Choiunard 2013). The following quote however, demonstrates scepticism that practitioners within this group held towards realist evaluation fitting in with wider practice:

I think it is probably more about the numbers for him (referring to partner organisation) because of Sport England and Sportivate, the government obviously, they need to get these numbers. Initially it was quite difficult and he didn't really understand what we actually found. It was more, oh, how many people attended or kind of that aspect (Louise, Interview). 
These examples highlight tensions surrounding working with fellow stakeholders in projects and reflect similar issues in the wider SfD industry surrounding partnership working and synthesising the disparate organisational goals for evidence. In this case realist evaluation's scope to elucidate context, and the mechanisms of change were perceived not to be high on the agenda for the partners. This highlights some tensions within the training framework concerning developing a shared understanding of the project with external partners that was required for realist approaches to be recognised. Nevertheless, what is apparent here is the way in which realist evaluation has been significantly grasped as a competent $\mathrm{M} \& \mathrm{E}$ approach. Indeed, whilst those in this group highlight scepticism in the recognition of the findings this can also be seen as a positive development in the practitioners questioning norms and practices around M\&E.

Practitioners within this group were able to identify problems, develop knowledge and show deeper reflexivity towards the realist evaluation. For example, practitioners were consciously able to identify problems with CMMOs such as how many configurations to examine and deciding what would constitute a context, mechanism or outcome (Dalkin et al. 2015):

Our big one was sometimes confusing or not understanding whether our context was the mechanism or whether the mechanism was the context. And that was our biggest one because I remember meeting John, sitting down, and he'd be like, to me, that's a mechanism, but I'd be like, Oh, to me, that's a context (Teresa, Interview).

This demonstrates the promotion of evaluative thinking (Schula et al. 2016) on two levels. Firstly, within the dimension of learning about how to mobilise the realist evaluation approach, and secondly in accordance with the increased interest and inquisitiveness on behalf of the practitioners. Archibald (2013) asserts that evaluative thinking encompasses learning and inquisitiveness and Schula et al. (2016) also suggest that when evaluative thinking is fostered, a culture of enquiry is nurtured amongst stakeholders. These findings illustrate the ways in which the practitioners have shown inquisitiveness towards and application of realist evaluation:

So actually finding out what the mums kind of gained or actually not from our project, finding out obviously again what worked for whom in what circumstances and why was massive for us (Louise, Interview).

On the practical level, there is evidence of changes in disposition towards the project aligned with new skills gained. On the transformative level, the practitioners have taken control as to how they view their project by moving away from traditional evangelical and outcomes approaches.

Despite the independent leadership and problem solving skills they possessed, practitioners still resided in a position of inexperience and limited knowledge for carrying out realist evaluation and $M \& E$ in general. As such, the contextual predefined design of the $M \& E$ training framework mobilised by the workshop resource provided the needed capacity building alongside the independence and conceptual engagement:

I think we kind of did need guidelines because otherwise you wouldn't know where to start. So for our project, I think we needed a starting point so we could then stem like different kind of mechanisms for the mums. So, we definitely needed that push to begin with (Louise, Interview). 
This illuminates the importance of clarifying the motivation for collaboration (Schula et al. 2016) because it was not a desire on behalf of the practitioners to build their own framework. The pre-designed realist evaluation training M\&E framework enabled a sound depth of participation and appeared to strike a good balance along the lines of control in decision making. This has implications for how realist evaluation may be mobilised with practitioners in other contexts, regarding how practitioners are consulted and engaged in any form of capacity building from the outset and how they are supported throughout the process.

Control in decision making reflected the fostering of meaningful inter professional relationships (Schula et al. 2016) where practitioners could call upon support and guidance when needed. The difference for group 2 practitioners concerned them not requiring as much control or support as those in other groups. Their assertive nature enabled them to go it alone in the $M \& E$ processes for longer, drawing upon the needed control and guidance of the trainer to keep them on track. 


\section{Holistic narrative:}

Practitioners represent key viewpoints that $M \& E$ should be a key part of a practitioner's role $(30+4)$ and continual professional development (15+4). This demonstrates transformational characteristics in that evaluation work should be centred within a practitioner's role.

Deeper interpretation of this group indicates that practitioners are less critical of the $M \& E$ landscape and are not as conscious of the challenges for practitioners doing this work. They are less reflexive (9-2) than those in groups 1 and 4 towards $M \& E$ so may not be as engaged (19-0). Their negative inclination to carry out $M \& E$ in the future (2-0) nor realist evaluation (3-1) are examples of this. There is little confidence (24-4) that their $M \& E$ findings have any impact, mainly due to their weaker reflexivity towards $M \& E$. The context of them being more attuned to coaching roles within their projects is also significant because it suggests that they favour the act of coaching opposed to conducting $M \& E$.

These practitioners have taken more of a surface-level approach to $M \& E$ where the process has enabled use that is reflected more so in the reliance on other practitioners. Viewpoints are neutral (10-0) regarding the importance of interacting with others to understand realist evaluation but, without the support of the training framework $(28+3)$ and those in their project, their grasping would be far more limited. Small glimpses appear where practitioners see the benefit of the stages underpinning the training framework supporting other areas. Nevertheless, they find it challenging to see the connection as to how the learning and deeper understanding of their project can be synthesised with M\&E findings.

Realist evaluation competency is not significant (3-1) nor is there any intention to carry it out in the future (3-1) because of issues with grasping realist evaluation terminology and jargon. This is further supported by the disengagement with the phases provided (7-3); (82). The picture emerging here concerns the shared viewpoints that there is no significant distance travelled as far as $M \& E$ competency is concerned. Practitioners appear more laid back about the training framework opposed to other groups and seem content to be guided by others $(28+3)$.

When asked (within the interviews) to clarify 'why' and 'how' they felt that they had developed a deeper understanding of mechanisms within their projects, practitioners were unable to draw upon some of the key realist principles provided by those in other groups. In this sense, unlike other groups (group 2) limited or no reference was made to 'mechanisms of change' or 'reasoning':

I think it was just a lot of the time it was like the terminology. Like, at first, I thought, realistically, like I didn't understand the realistic evaluation approach, so I was like -I 
Because of the academic implications of being involved in the project and what was at stake, this context led to motivation to improve one's attainment by making use of the workshops. It was also apparent that looking towards others in their project for guidance to achieve this end was common amongst these practitioners.

\begin{abstract}
In terms of promoting evaluative thinking, practitioners did not express any sufficient degree of reflexivity or critical engagement with realist evaluation. In the case of this outcome, the mechanism of distinguishing between $M \& E$ for the purpose of their project was far more pertinent than fostering inquisition and deeper reflection about their evidence. Therefore, within this group it would be naïve to conjecture that they would be likely to elicit $M \& E$ in future roles, especially given that they had little faith about where their findings would go.

Like other groups, the context concerning limited experience in $M \& E$ was very much relevant to this group. However, unlike practitioners in other groups the resources associated with the terminology of realist evaluation such as 'CMMO configurations' and 'programme theory' created confusion and the inability to grasp certain concepts, (as supported by the previous and following quote):
\end{abstract}

I think obviously we were all engaged. But I personally felt I was less engaged, just maybe because I didn't seem to understand it a lot more. Like when we're having the discussions, it did seem as if, the other lads knew a little bit more about it. And I'm not sure, it's just maybe that they might have read a little bit more than I did (Mark, Interview).

This limited grasping of realist terminology was a disempowering mechanism for a number of reasons. One explanation relates to the surface learning approach taken and relying on fellow practitioners within the project to deal with such concepts. Another explanation, however, may demonstrate key issues for practitioners in making sense of high-level conceptual terms (such as 'context' and 'mechanism') which may immediately disengage practitioners. In this case such explanations help to explain why the practitioners were less optimistic about eliciting realist evaluation in the future practice. Thus, this has implications for how such terminology and jargon is introduced to practitioners in SfD if they are to engage with realist evaluation and its philosophical connotations.

In addition, if it was not for those within other groups undertaking leadership roles, practitioners in this group would have struggled considerably to make use of the training framework. This reiterates the importance for any collaborative framework's ability to firstly monitor and respond to resource availability (Schula et al. 2016). If not for those supporting them in their projects, these practitioners, and their limited grasping of realist evaluation may have required additional monitoring of progress and quality. This demonstrates important considerations for the SfD field and mobilising of realist evaluation given that, across many projects, SfD personnel consist of volunteers and coaches in addition to practitioners (Lindsey and Gratton 2012, Kay 2012). For any framework to be effective, the capacity of those in such roles and their motivation need to be understood so that appropriate participatory processes can be mobilised (Schula et al. 2016). 


\section{Holistic narrative:}

The $M \& E$ training framework facilitated the mobilisation of $M \& E(18+4)$ for the practitioners. Without the structure of the training framework $(28+3)$ and opportunity to apply it in practice they would have found the process of evaluating their project challenging. Practitioners share views that the relationship with the trainer enabled deeper understanding of doing $M \& E(17+3)$ and that there is a mutual understanding of programme evaluation goals $(23+2)$. This indicates that mutual understanding and trust exists between the trainer and practitioners. They are able to shape their $M \& E$ design within the training framework. Like groups 2 and 1, viewpoints associated with control suggest that they do not feel in control of the evaluation. This is associated not with the building of the evaluation and participation in the training framework itself, but mobilising the evaluation within their own project. For them, the context of their project was often subject to change, involving young people, and this made it hard for them to mobilise $M \& E$ as they initially intended.

Realist evaluation is not significantly favoured as an evaluation approach. They are less likely than any other group to carry out realist evaluation in the future (14-3) partly because of apprehension towards developing programme theory (6-1) and using the phases to develop it (7-3). This is relevant in terms of the compatibility of the context of the programme and $M \& E$ design. Practitioners, whilst recognising the benefit of realist evaluation, are also reflexively aware of its limitations.

Their motivation for engaging in the training framework was initially on the basis that the it would enable them to get the job of the $M \& E$ done. However, the affordance of time and engagement in the stages of the training framework, fostered motivation to develop an understanding of why their project would meet certain outcomes, beyond proving project success. They have demonstrated critical engagement in the $M \& E$ process because they have made an effort to make use of resources $(16+1)$ and are more reflexive about how they would embark on $M \& E$ in the future $(9+2)$.

On a transformational level, more than any other group, they feel that their findings will be valued by others (24+4) partly because they have taken pride in their achievements. They feel that their findings are likely to have an impact because the approach taken has uncovered new knowledge, which suggests that realist evaluation has been able to evoke findings that will be recognised externally, influencing future practice within the workings of partners.

Practitioners within this group placed emphasis on the importance of a flexible capacity building process provided by the trainer to enable the fruition of $M \& E$ :

The trainer was very flexible which really suited us. You weren't really forced into it. You say that, "Oh you can't turn up to the workshop, or we can arrange another time." So, 
you're very flexible in that way. In terms of my understanding of $M \& E$, I like the fact we work through stages (Nathan, Interview).

Within the context of limited understanding of $M \& E$ and awareness of realist evaluation, practitioners made effective use of the workshops and support of the trainer because of the mutual trust and engagement and knowledge on behalf of the trainer to provide needed guidance:

I think I needed it, yeah. And even when we didn't have a scheduled time to meet with the trainer, if any of us really had any queries about how or where we go from, where we go from somewhere, we would just arrange a tutorial and talk it through and go from there (Robert, Interview).

The high value placed upon trust was strongly associated with the need to ensure that the trainer and practitioners had a clear understanding of what the project was about. In order to allow sufficient grasping of realist evaluation, supportive environments such as these may be crucial for practitioners to enact such approaches within SfD, especially around understanding the key terms that realist evaluation presents.

Practitioners were optimistic about the value afforded to their findings more than any other group. Interestingly, the practitioners were operating within the context of a contemporary physical literacy project with a limited evidence base underpinning it. Utilising realist evaluation helped them to identify new knowledge associated with certain learning styles of their participants which in turn they felt would enhance the use for their project. This was because of the way in which realist approaches are able to dig deeper for crucial aspects of reasoning thanks to the nature of questions explored, which subsequently enables project refinement (Pawson and Tilley 1997):

And I feel our evaluation actually led to a different approach in the school because they used to work with a class of 30. Now they split the class. They split the people who are only like kinaesthetic kind of learner. They weren't doing that before but it's only thanks to sort of our project that they've done that (Nathan, Interview).

Where group two was more transformational in respect to practitioner use of realist evaluation, the use of findings and their impact were key here for practitioners in this group. This was associated with the high value placed upon their findings and influence they felt they would have upon their stakeholders. Transformational impact was very strong in regard to how increasingly more engaged they had become in the $\mathrm{M} \& \mathrm{E}$ as a result of the capacity building developed within the training framework:

Obviously in the beginning it was just to be honest, get good grades, things like that. But towards the end it's something...like I've said I've gained a lot from it. I wouldn't have cared at the beginning but obviously having more time to understand monitoring and evaluation as something I've previously struggled with. Now I've been through the framework, it's really helped me to become more reflective myself (Nathan, Interview).

This enabled changes of disposition towards their project (Schula et al. 2016) and subsequent learning. This was the key mechanism leading to greater reflexivity and value afforded to going beyond traditional technocratic approaches to M\&E (Choiunard 2013; Harris and 
Adams 2016). In similar respects to other groups, this finding demonstrates the scope of realist evaluation in illuminating programme learning due to its power to elucidate reflexivity and generative causation. Moreover, in this case it also captures the potential for realist evaluation to actually influence partners to recognise the value of the evidence it produces.

Despite the transformational aspects, this group also expressed reservations about realist evaluation. Despite possessing a strong conceptual grasp of realist evaluation, practitioners within this group were more cautious about its use given conceptual terminology and application to the project. This can be connected with the context of their project which involved young people. It was made apparent that trying to explore and unearth mechanisms of change with young people was a challenge:

What is it about our approach that can enhance children's behaviour within the classroom? I'm not sure if we fully achieved this. With regards to the feedback gained from the children, it was of a limited nature because of their age and expression (Robert, Interview).

Trying to unearth the generative causal mechanisms (Pawson and Tilley 1997) with this sample created problems; first, in encouraging the young people to open up about their views (which also relates to ethical implications around sensitivity) and, second the time it takes to unearth such mechanisms (which is a challenge in education settings). This mobilisation of realist evaluation obviously has interesting implications for the SfD field which, in many cases, involves working with children and adolescents. This does not necessarily mean that realist evaluation is inadequate for projects with this target group. On the contrary, providing appropriate ethical procedures are followed with substantial time and method factored in, scope exists for mobilising realist evaluation. Indeed, uncovering such mechanisms with young people is not solely dependant on engaging with them directly and can also involve other sampling approaches such as teachers and parents. Overall, such a finding is a key sign of engagement with realist evaluation in the sense of understanding that realist evaluation goes beyond simple observation (Pawson and Tilley, 1997). This engagement with realist evaluation has fostered curiosity and an appraisal of the approach. Whilst members of this group did not rule out using realist evaluation in the future, this did lead to a more cautious opinion as to whether they would make use of it.

\section{Conclusion}

This paper has attempted to explore how a training framework focused on building the capacity in realist evaluation can work for practitioners in their SfD projects. Despite disparity of engagement with the training framework, the positive synthesis of realist evaluation with collaborative approaches show potential for developing and fostering realist methodologies for M\&E with practitioners. There have been a series of examples across the groups presented whereby adopting realist evaluation has fostered greater learning of how the practitioners see their projects working, as well as how it can improve their projects. The realist evaluation approach has enabled the practitioners to develop an evidence-base for their project whilst occupying a higher level of consciousness surrounding the approach and how it may influence the SfD landscape. This clearly has positive implications for any mobilisation in the field with practitioners given the capacity of realist evaluation to demystify the 'black box' and build an evidence-base for how and why programmes work. While this emerges at a time where certain M\&E methodologies must compete with others, there is resonance across 
industries such as health (Dalkin et al. 2015, Westhorp 2014) and SfD (Coalter 2013a, Harris and Adams3 2016) that realist approaches could be explored.

It is important to recognise that the training framework worked for different practitioners in different ways, and in some respects challenges arose surrounding its utility, particularly through its complex language and suitability for certain target groups. The implications here would illustrate the importance of suitable and appropriate collaborative frameworks (like the one in this study) to provide supportive and trust fostering environments.

Ultimately, a key question residing over work of this nature concerns to what extent practitioners should, and have the capacity to, carry out M\&E. A rationale has been asserted for involving them more closely within the M\&E process. The findings informing this paper demonstrate that the training framework has capacity for enabling practitioners to mobilise M\&E. In the case of this training framework, differing variations of practitioners were able to demonstrate degrees of reflexivity and transformation. This is powerful within the context of SfD given the current context of an evidence base for sport which is currently underdeveloped (Edwards 2015; Sherry et al. 2014). This demonstrates the role that practitioners may have (depending on the context) in mobilising realist M\&E approaches to understand how and why programmes work.

\section{References}

Abhyankar, P., Cheyne, H., Maxwell, M., Harris, F. and McCourt, C. 2013, A realist evaluation of a normal birth programme. Evidence-Based Midwifery (Royal College of Midwives), 11 (4), 112-120. Available from: https://search.proquest.com/docview/1470776405.

Adams, A., 2008. Building Organisational and Management Capacity for the Delivery of Sports Development. In: V. Girginov, ed, Management of Sports Development. Elsevier Science \& Technology, Oxford, 201-224.

Archibald, T. 2013. Free range evaluation: Evaluative thinking [online]. Available: http://evalcentral.com/2016/01/06evaluative-thinking/ [Accessed 24th May 2015].

Astbury, B., and Leeuw, F.L., 2010. Unpacking Black Boxes: Mechanisms and Theory Building in Evaluation. American Journal of Evaluation, 31 (3), 363-381. Available from: http://journals.sagepub.com/doi/full/10.1177/1098214010371972.

Bell, B., 2010. Building a legacy for youth and coaching, In: M.Collins, ed, Examining Sport Development. Routledge, 139-159.

Bloyce, D., Smith, A., Mead, R., and Morris, J., 2008. Playing the Game (Plan): A Figurational Analysis of Organizational Change in Sports Development in England. European Sport Management Quarterly, 8 (4), 359-378. Available from: http://www.tandfonline.com/doi/abs/10.1080/16184740802461637.

Brown, S.R., 1980. Political subjectivity. Yale Univ. Press: New Haven

Bruening, J., Welty Peachey, J., Evanovich, J., Fuller, R., Murty, C., Percy, V., Silverstein, L., and Chung, M., 2015. Managing sport for social change: The effects of intentional 
design and structure in a sport-based service learning initiative. Sport Management Review, 18 (1), 69-78. Available at: https://search.proquest.com/docview/1655112282.

Byrne, D., and O'Callaghan, G., 2013. Complexity Theory and the Social Sciences. The state of the art. Abingdon, Oxon: Routledge.

Cabinet Office, 2015. Sporting future: a new strategy for an active nation. London: Cabinet Office.

Chouinard, J.A., 2013. The Case for Participatory Evaluation in an Era of Accountability. American Journal of Evaluation, 34 (2), 237-253. Available from: http://journals.sagepub.com/doi/full/10.1177/1098214013478142.

Coalter, F., 2013a. There is loads of relationships here: Developing a programme theory for sport-for-change programmes. International Review for the Sociology of Sport, 48 (5), 594-612. Available from: http://journals.sagepub.com/doi/full/10.1177/1012690212446143.

Coalter, F., 2013b. Sport for development - What game are we playing. London: Routledge.

Coalter, F., 2010. The politics of sport-for-development: Limited focus programmes and broad gauge problems? International Review for the Sociology of Sport, 45 (3), 295-314. Available from: http://journals.sagepub.com/doi/full/10.1177/1012690210366791.

Coalter, F., 2007. A Wider Social Role for Sport: Who's Keeping the Score? London: Routledge.

Cousins, J.B., and Whitmore, E., 1998. Framing participatory evaluation. New Directions for Evaluation, 1998, (80), 5-23.

Cousins, J.B., Whitmore, E., and Shulha, L., 2014. Let There Be Light. American Journal of Evaluation, 35, (1), 149-153. Available from: http://journals.sagepub.com/doi/full/10.1177/1098214013510200.

Cousins, J.B., Whitmore, E., and Shulha, L., 2013. Arguments for a Common Set of Principles for Collaborative Inquiry in Evaluation. American Journal of Evaluation, 34, (1), 7-22. Available from: http://journals.sagepub.com/doi/full/10.1177/1098214012464037.

Crabbe, T., 2007. Positive Futures: Putting the Pieces Together? The 2007 Annual Positive Futures Monitoring and Evaluation Report. Home office: London

Dalkin, S.M., Greenhalgh, J., Jones, D., Cunningham, B., and Lhussier, M., 2015. What's in a mechanism? Development of a key concept in realist evaluation. Implementation science 10, (49), 49-57. Available from: http://www.ncbi.nlm.nih.gov/pubmed/25885787.

Department of Culture, Media and Sport/Strategy Unit., 2002. A Sporting Future For All. Department of Culture, Media and Sport/Strategy Unit: London.

Duffy, P., North, J., and Muir, B., 2013. Understanding the impact of sport coaching on legacy. International Journal of Sport Policy and Politics, 5 (2), 165-182.

Edwards, M., 2015. The role of sport in community capacity building: An examination of sport for development research and practice. Sport Management Review, 18 (1), 6-14. Available from: https://search.proquest.com/docview/1655112292. 
Fetterman, D.M., 2001. Foundations of empowerment evaluation. Thousand Oaks, Calif. Sage

Funnell, S.C., and Rogers, P.J., 2011. Purposeful Program Theory. US: Jossey-Bass

Harris, K., and Adams, A., 2016. Power and discourse in the politics of evidence in sport for development. Sport Management Review, 19 (2), 97-106.

Hayton, J., 2017. They do treat us as a bit normal now. Students' experiences of liminality and communitas whilst volunteering on a sports based outreach project. International Review for the Sociology of Sport, 1-21. Available from DOI: 10.1177/1012690216687553

Houlihan, B., White, A., 2002. The politics of sports development: development of sport or development through sport? Routledge.

Hylton, K., and Hartley, H.J., 2011. Sports Development...a profession in waiting? In: S. Harris., B. Bell., A. Adams., and C. Mackintosh, ed. Sport for Sport? Practical and Theoretical Insights in Sports Development. Brighton: LSA Publication 117,.

Jagosh, J., Macaulay, A., Pluye, P., Salsberg, J., Bush, P., Henderson, J., Sirett, E., Wong, G., Cargo, M., Herbert, C., Seifer, S., Green, L.W., and Greenhalgh, T., 2012. Uncovering the Benefits of Participatory Research: Implications of a Realist Review for Health Research and Practice. The Milbank Quarterly, 90 (2), 311-346. Available from: http://www.jstor.org/stable/23266513.

Kay, T., 2012. Accounting for legacy: monitoring and evaluation in sport in development relationships. Sport in Society, 15 (6), 888-904. Available from: http://www.tandfonline.com/doi/abs/10.1080/17430437.2012.708289.

Kay, T., 2009. Developing through sport: evidencing sport impacts on young people. Sport in Society, 12 (9), 1177-1191. Available from: http://www.tandfonline.com/doi/abs/10.1080/17430430903137837.

Kidd, B., 2010. Epilogue: the struggles must continue. Sport in Society, 13 (1), 157-165. Available from: http://www.tandfonline.com/doi/abs/10.1080/17430430903377995.

Levermore, R., 2011. Evaluating sport-for-development. Progress in Development Studies, 11 (4), 339-353. Available from: http://journals.sagepub.com/doi/full/10.1177/146499341001100405.

Lindsey, I., and Grattan, A., 2012. An 'international movement? Decentring sport-fordevelopment within Zambian communities. International Journal of Sport Policy and Politics, 4, (1), 91-110. Available from: http://www.tandfonline.com/doi/abs/10.1080/19406940.2011.627360.

Manzano, A., 2016. The craft of interviewing in realist evaluation. Evaluation, 22 (3), 342360. Available from: http://journals.sagepub.com/doi/full/10.1177/1356389016638615.

McConnell, T., Scott, D., and Porter, S., 2016. Healthcare staff's experience in providing end-of-life care to children: A mixed-method review. Palliative Medicine, 30 (10), 905919. Available from: http://journals.sagepub.com/doi/full/10.1177/0269216316647611. 
Mwaanga, O., 2011. Understanding and Improving Sport Empowerment for People Living with HIV/AIDS in Zambia. Thesis (PhD). Leeds Metropolitan University.

Nicholls, S., Giles, A.R., and Sethna, C., 2011. Perpetuating the 'lack of evidence' discourse in sport for development: Privileged voices, unheard stories and subjugated knowledge., International Review for the Sociology of Sport, 46 (3), 249-264. Available from: http://journals.sagepub.com/doi/full/10.1177/1012690210378273.

Nichols, G., 2007. Reflections on researching the ability of sports interventions to reduce youth crime - the hope of scientific realism. In: K. Hylton, J Long, and A Flintoff, ed. Evaluating Sport and Active Leisure for Young People. Publication No. 88 ISBN: 978-0906337-99-8.

Pawson, R., and Tilley, N., 1997. Realistic evaluation. London: Sage.

Piggin, J., Jackson, S.J., and Lewis, M., 2009. Knowledge, Power and Politics. International Review for the Sociology of Sport, 44, (1), 87-101 Available from: http://journals.sagepub.com/doi/full/10.1177/1012690209102825.

Richards, I., Muir, B., Duffy, P., North, J., and Boocok, E., 2012. International community Coach Education Systems (ICES) Research Project Report. Leeds Metropolitan University

Sherry, E., Schulenkorf, N., and Chalip, L., 2014. Managing sport for social change: The state of play. Sport Management Review, 18 (1), 11-21.

Shulha, L.M., Whitmore, E., Cousins, J.B., Gilbert, N., and al Hudib, H., 2016. Introducing Evidence-Based Principles to Guide Collaborative Approaches to Evaluation. American Journal of Evaluation, 37 (2), 193-215. Available from: http://journals.sagepub.com/doi/full/10.1177/1098214015615230.

Smith, A., and Leech, R., 2010. Evidence. What evidence? evidence-based policy making and School Sport Partnerships in North West England. International journal of sport policy and politics, 2 (3), 327-345. Available from: http://www.fachportalpaedagogik.de/fis_bildung/suche/fis_set.html?FId=941620.

Sugden, J., 2010. Critical left-realism and sport interventions in divided societies. International Review for the Sociology of Sport, 45 (3), 258-272. Available from: http://journals.sagepub.com/doi/full/10.1177/1012690210374525.

Tilley, N., 2000. Realistic evaluation: An overview, The founding conference of the Danish evaluation society keynote talk.

Watts, S., and Stenner, P., 2012. Doing Q methodological research. Los Angeles: Sage.

Watts, S., and Stenner, P., 2005. Doing Q methodology: theory, method and interpretation. Qualitative Research in Psychology, 2 (1), pp. 67-76. Available from: http://www.tandfonline.com/doi/abs/10.1191/1478088705qp022oa.

Weed, M., 2016. Should we privilege sport for health? The comparative effectiveness of UK Government investment in sport as a public health intervention. International journal of sport policy and politics, 8 (4), 559-576. Available from: http://www.fachportalpaedagogik.de/fis_bildung/suche/fis_set.html?FId=1110946. 
Welty Peachey, J., Borland, J., Lobpries, J., and Cohen, A., 2015. Managing impact: Leveraging sacred spaces and community celebration to maximize social capital at a sport-for-development event. Sport Management Review, 18 (1), 86-98. Available from: https://search.proquest.com/docview/1655112402. 